\title{
NMR-based stable isotope resolved metabolomics in systems biochemistry
}

\author{
Teresa W-M. Fan and \\ Department of Chemistry, University of Louisville, Louisville, KY, USA \\ Center for Regulatory Environmental Analytical Metabolomics, University of Louisville, Louisville, \\ KY, USA
}

JG Brown Cancer Center, University of Louisville, Louisville, KY, USA

Andrew N. Lane

Center for Regulatory Environmental Analytical Metabolomics, University of Louisville, Louisville, KY, USA

JG Brown Cancer Center, University of Louisville, Louisville, KY, USA

Rm 217, CTRB, 505 S. Hancock St., Louisville, KY 40202, USA

\section{Abstract}

An important goal of metabolomics is to characterize the changes in metabolic networks in cells or various tissues of an organism in response to external perturbations or pathologies. The profiling of metabolites and their steady state concentrations does not directly provide information regarding the architecture and fluxes through metabolic networks. This requires tracer approaches. NMR is especially powerful as it can be used not only to identify and quantify metabolites in an unfractionated mixture such as biofluids or crude cell/tissue extracts, but also determine the positional isotopomer distributions of metabolites derived from a precursor enriched in stable isotopes such as ${ }^{13} \mathrm{C}$ and ${ }^{15} \mathrm{~N}$ via metabolic transformations. In this article we demonstrate the application of a variety of 2-D NMR editing experiments to define the positional isotopomers of compounds present in polar and non-polar extracts of human lung cancer cells grown in either $\left[\mathrm{U}-{ }^{13} \mathrm{C}\right]$-glucose or $\left[\mathrm{U}-{ }^{13} \mathrm{C},{ }^{15} \mathrm{~N}\right]$-glutamine as source tracers. The information provided by such experiments enabled unambiguous reconstruction of metabolic pathways, which is the foundation for further metabolic flux modeling.

\section{Keywords}

Stable isotope resolved metabolomics; Isotope editing

\section{Introduction}

Metabolomics technologies are rapidly being established as a valuable set of tools for understanding biochemical regulation in organisms under normal and stress conditions. The rapid improvements in instrumentation and chemometrics have made it possible to identify and quantify a large number of metabolites in unfractionated cell or tissue lysates or 
biofluids, using appropriate analytical platforms (Fan et al. 1986; Maaheimo et al. 2001; Emmerling et al. 2002; Lindon et al. 2004; Fan et al. 2008; Lane et al. 2008). For most practical purposes, the two major platforms are mass spectrometry and NMR.

Although moderate sample throughput is straightforward with these technologies, of the order 25-50 samples per day when running under automation, the extraction of information from the extremely rich data sets remains problematic. One solution has been largely to ignore the identities of the compounds present, and simply focus on the differences between sets of samples using unsupervised statistics (Lindon et al. 2004; Trygg et al. 2007). However, to derive biochemical information and mechanistic understanding, the identities of the compounds must be known.

Furthermore, because biochemical networks are highly interlinked, intracellular concentrations are maintained within fairly narrow limits (homeostasis), and many metabolites participate in numerous common pathways, determination of metabolite concentrations alone is not sufficient to establish the biosynthetic routes unambiguously, as illustrated in Fig. 1. To place a metabolite in a given segment of a metabolic network, it is essential to use tracer technology, for which MS and NMR are ideally suited when the tracers are stable isotopes of common biological elements, such as ${ }^{2} \mathrm{H},{ }^{13} \mathrm{C}$, and ${ }^{15} \mathrm{~N}$.

Mass spectrometry is a universal detector of ionized compounds, and some mass spectrometers have very high resolution (sub ppm resolution) and sensitivity (fmol or less detection limit). For this reason it is often the technique of choice for high throughput metabolomics. MS can easily distinguish molecules that differ by one atomic mass unit, and thus can be used to measure mass isotopologues of metabolites. The highest resolution spectrometers such as Fourier transform ion-cyclotron-resonance (FT-ICR) MS can resolve differences in mass equivalent to differences in nuclear binding energy. Despite these advantages, MS cannot readily discern stable isotopes such as ${ }^{13} \mathrm{C}$ labeled at different atomic positions, e.g. Ala labeled at $\mathrm{C}-1,2$, or 3 positions. The exceptions are metabolites that can be extensively fragmented to provide information on labeled positions, but this is not a general case and can lead to a significant loss in sensitivity. In contrast, NMR readily determines each positional isotopomer as a distinct species without the need for fragmentation, i.e. at natural abundance appropriate NMR techniques produce distinct resonances corresponding to each single ${ }^{13} \mathrm{C}$ position. The disadvantage of NMR is its relatively low sensitivity, such that at least nmol amounts of each compound is needed for reliable measurement. Nevertheless, the unique capabilities of NMR for positional isotopomer determination are complementary to MS for the analysis of mass isotopologues, both of which are essential to resolving the complexity of metabolic networks.

A major step forward in the application of NMR to structure analysis was the development of 2-D methods that enabled much more straightforward and rigorous structural elucidation while improving the resolution, thereby greatly expanding the size range and complexity of molecules that could be studied (Ernst et al. 1990; Cavanagh et al. 2007). The combination of multidimensional methods with substitution of magnetically active stable isotopes, especially ${ }^{13} \mathrm{C}$ and ${ }^{15} \mathrm{~N}$, along with indirect detection further extended the size and complexity of molecular systems that could be studied (Clore and Gronenborn 1998a, b; Gardner and Kay 1998; Cavanagh et al. 2007). In most instances, uniform labeling was used, usually via the metabolism of microorganisms in which the protein is over expressed (Gardner and Kay 1998), but later semi-selective labeling approaches became common (Lundstrom et al. 2007). The incorporation of the alternative isotopes makes it possible to design a wide variety of spectral editing experiments (Gardner and Kay 1998). In metabolic studies however, the goal is to delineate which atoms in individual metabolites have been substituted during the metabolic transformations, which in essence is an inverse problem. 
Nevertheless, the use of stable isotope tracing in defining metabolic pathways, has a long history, dating back to 1935 (Rittenberg and Schoenheimer 1937).

Another important difference between macromolecular NMR and metabolic NMR is that in the former usually a pure compound of known composition and stoichiometry is studied. In contrast, in metabolomics it is the identity of the components, and their isotopomer distributions in a mixture that are to be determined.

Nevertheless, stable isotope tracing in unfractionated mixtures of metabolites (loosely defined as biomolecules of molecular mass $\mathrm{M}<1,000 \mathrm{Da}$ that are subject to enzymatic transformation) has been enabled by the same developments in high field, multinuclear and multi-dimensional NMR techniques, which have proven utility in macromolecular structural elucidation. We have applied some of the common 2-D editing experiments to determine phosphorylated metabolites (Gradwell et al. 1998), and to profile composition of labeled isotopomers indirectly using proton detection in ${ }^{13} \mathrm{C}$ and ${ }^{15} \mathrm{~N}$ tracer studies in microbes (Fan et al. 2009a, b), plants (Fan 1996), and human tumor metabolism (Fan et al. 2005, 2008, 2009a, b, 2010; Lane et al. 2009). Here we extend this approach using additional editing techniques to determine the structural topology of the stable isotopic enrichment in metabolites directly in a complex mixture.

\section{Materials and methods}

\section{Materials}

Human lung adenocarcinoma A549 cells were cultured in RPMI media containing 10.75 $\mathrm{mM}\left[\mathrm{U}-{ }^{13} \mathrm{C}\right]$-glucose (Sigma-Aldrich, St. Louis) and 10\% dialyzed fetal calf serum as previously described (Fan et al. 2005). Polar metabolites were extracted using 60\% cold acetonitrile, freeze dried and then redissolved in $99.9 \% \mathrm{D}_{2} \mathrm{O}$ for NMR analysis (Fan 2010). $30 \mathrm{nmol}$ DSS-d6 (Sigma-Aldrich, St. Louis) were added to samples (771 $\mu \mathrm{M}$ methyl protons) as a shift reference and concentration standard. $\left[\mathrm{U}^{13} \mathrm{C},{ }^{15} \mathrm{~N}\right]$-Glutamine was purchased from Sigma-Aldrich (St. Louis) and used without further purification. All other reagents were of cell culture grade.

Polar lipids were extracted from cells using methanol containing $1 \mathrm{mM}$ butylated hydroxytoluene (BHT), vacuum-dried, and redissolved in $99.98 \%$ methanol $\mathrm{d}_{4}$ for NMR analysis, as previously described (Lane et al. 2009). Chemical shifts were referenced to the methanol resonance at $3.31 \mathrm{ppm}$.

\section{Methods}

NMR spectra were recorded at $293 \mathrm{~K}$ on Varian Inova spectrometers at either $14.1 \mathrm{~T}$ or 18.8 $\mathrm{T}$.

1D NMR spectra were recorded with weak presaturation of the solvent resonance with an acquisition time of $2 \mathrm{~s}$ and a recycle time of $3 \mathrm{~s}$.

The following isotope edited 2D experiments were carried out to quantify enrichment at specific atoms and/or to detect specific isotopomers: ${ }^{1} \mathrm{H}\left\{{ }^{13} \mathrm{C}\right\}$-HSQC, HSQC-TOCSY, HCCH-TOCSY, HACACO; ${ }^{1} \mathrm{H}\left\{{ }^{31} \mathrm{P}\right\}$ HSQC-TOCSY $;{ }^{1} \mathrm{H}\left\{{ }^{15} \mathrm{~N}\right\}$-HSQC-TOCSY and ${ }^{1} \mathrm{H}-{ }^{1} \mathrm{H}$ TOCSY.

High-resolution ${ }^{1} \mathrm{H}\left\{{ }^{13} \mathrm{C}\right\}$-HSQC spectra were recorded with acquisition time of $0.15 \mathrm{~s}$ in $t_{2}$ and $40 \mathrm{~ms}$ in $t_{1}$. After linear prediction and zero filling the resolution in $\mathrm{F} 1$ was $6-8 \mathrm{~Hz} /$ point, which is adequate to resolve ${ }^{1} \mathrm{~J}_{\mathrm{CC}}$ of ca. $45 \mathrm{~Hz}$. GARP decoupling was applied during the proton acquisition. 
The HACACO experiment was performed with different ${ }^{13} \mathrm{C}$ offsets to select either for the $\mathrm{C} \alpha$ or the $\mathrm{C} \beta / \mathrm{C} \gamma$ of Glu/Asp (Jeng and Dyson 1996; Qin et al. 1996), and recording the HA$\mathrm{CO}$ and $\mathrm{H}-\mathrm{CA} / \mathrm{CB}$ planes.

\section{Results and discussion}

\section{Analysis of polar metabolites}

${ }^{1} \mathbf{H}$ detection-The primary advantage of proton detection over direct $\mathrm{X}$ detection is sensitivity. We have applied a number of common proton-detected 2-D NMR experiments to identify and quantify positional enrichment of ${ }^{13} \mathrm{C}$ and ${ }^{15} \mathrm{~N}$ in metabolites present in unfractionated extracts of only a few $\mathrm{mg}$ of cancer cells by dry weight. This approach circumvented the need for chromatographic separation.

As we have previously described, cross-peak satellite patterns in TOCSY spectra provide quantitative estimates of the enrichments at different atomic positions of metabolites, where the protons are directly bonded to ${ }^{13} \mathrm{C}$ or ${ }^{15} \mathrm{~N}$ (Lane and Fan 2007; Fan and Lane 2008; Lane et al. 2008). Figure 2 shows an example TOCSY spectrum of a polar extract of A549 cells grown in the presence of $\left[\mathrm{U}-{ }^{13} \mathrm{C}\right]$-glucose. The red rectangles connect the cross-peaks of protons attached to ${ }^{12} \mathrm{C}$. The green dashed boxes trace the ${ }^{13} \mathrm{C}$ satellite peaks arising from the attached ${ }^{13} \mathrm{C}$ atoms for a pair of correlated protons. For example, lactate and the ribose moieties of the free nucleotides show isotopomers with either no ${ }^{13} \mathrm{C}$ (central cross-peak) or both atoms are ${ }^{13} \mathrm{C}$ (square array) (Lac-H2/3 $3_{\text {sat }}, 5^{\prime} \mathrm{AXP}-\mathrm{H} 1^{\prime} / 2^{\prime}{ }_{\text {sat }}$, UDPGH1'/2 ${ }_{\text {sat }}$, and NAD ${ }^{+}$ - H1'/2' sat in Fig. 2b). In contrast, the cross-peaks of glutamate and the glutamyl moiety of glutathione (GSH) displayed more complex patterns, that correspond to a mixture of four isotopomers comprising the fragments ${ }^{12} \mathrm{C} 3{ }^{12} \mathrm{C} 4,{ }^{13} \mathrm{C} 3{ }^{13} \mathrm{C} 4$ (Glu-H3/4 sat), ${ }^{12} \mathrm{C} 3{ }^{13} \mathrm{C} 4$ (Glu$\mathrm{H} 4$ sat $)$, and ${ }^{13} \mathrm{C}^{12} \mathrm{C} 4\left(\mathrm{Glu}-\mathrm{H} 3_{\text {sat }}\right)$. As these cross-peaks can be volume integrated, the relative abundance of the positional labeling can be determined with reasonable accuracy, as shown in Table 1 (Lane and Fan 2007). The uracil rings of uridinediphosphoglucose (UDPG) also exhibited similar cross-peak patterns as those of Glu (see above), indicating ${ }^{13} \mathrm{C}$ at either $\mathrm{C} 5$ (UDPG-H5 $5_{\text {sat }}$ ) or C6 (UDPG-H6 $6_{\text {sat }}$ ) and at both $\mathrm{C} 5$ and $\mathrm{C} 6$ (UDPG-H5/6 $6_{\text {sat }}$, Fig. 2d). The ribose rings of NAD ${ }^{+}$showed a fully labeled plus unlabeled cross-peak patterns (Fig. 2a), but the nicotinamide ring displayed no labeled pattern (Fig. $2 \mathrm{~d}$ ), as expected since it is derived from the vitamin niacin.

${ }^{13} \mathrm{C}$ editing-As ${ }^{1} \mathrm{H}-{ }^{1} \mathrm{H}$ TOCSY experiments do not detect ${ }^{13} \mathrm{C}$ with no attached protons (e.g. quaternary or carbonyl carbons), the ${ }^{1} \mathrm{H}\left\{{ }^{13} \mathrm{C}\right\}$-HSQC experiment is a useful, complementary experiment. When recorded at high resolution in F1, the HSQC experiment shows the ${ }^{13} \mathrm{C}-{ }^{13} \mathrm{C}$ couplings from which it is possible to infer the presence of label at quaternary or carbonyl carbons (Fig. 3). However, this experiment provides little information concerning the level of enrichment, unless careful peak shape analysis is carried out as is necessary for direct ${ }^{13} \mathrm{C}$ detection experiments (Lu et al. 2002; Sherry et al. 2004). Nevertheless, the appearance of ${ }^{13} \mathrm{C}$ doublets for Glu-C4 implies that this metabolite was present mainly as either ${ }^{13} \mathrm{C} 4{ }^{13} \mathrm{C} 5$ or ${ }^{13} \mathrm{C} 3{ }^{13} \mathrm{C} 4$, but as Glu-C3 showed no splitting (Fig. 3a, b), it is most likely that ${ }^{13} \mathrm{C} 4{ }^{13} \mathrm{C} 5$ was the more abundant species. This is consistent with the condensation of glucose-derived ${ }^{13} \mathrm{C}_{2}$-acetyl CoA with unlabeled OAA, which subsequently leads to the production of ${ }^{13} \mathrm{C}-4,5-\mathrm{Glu}$ in the first turn of the Krebs cycle (Fan et al. 2010). It is also notable that the glutamyl moiety of reduced GSH showed the same splitting pattern as free glutamate, implying de novo biosynthesis of GSH from the free glutamate pool. Similarly, the splitting patterns of the 2'- to 4 'carbons of the nucleotide ribose were triplets while that of the $1^{\prime}$ carbon was a doublet (Fig. 3c, d), which is consistent with uniform labeling of the nucleotide riboses via the pentose phosphate pathway (PPP). 
The splitting patterns of $\mathrm{C} 3$ and $\mathrm{C} 2$ of lactate were a doublet and triplet, respectively (Fig. 3a-d), which indicates that lactate was uniformly ${ }^{13} \mathrm{C}$ labeled, and therefore derived from $\left[\mathrm{U}-{ }^{13} \mathrm{C}\right]$-glucose via glycolysis and to a lesser extent via the non-oxidative branch of the PPP, which is typically active in cancer cells (Boren et al. 2001; Lee et al. 1998). Moreover, the triplet pattern of $\mathrm{C} 2$ of Asp (Fig. 3a, b) suggests the presence of ${ }^{13} \mathrm{C} 1,{ }^{13} \mathrm{C} 2,{ }^{13} \mathrm{C} 3$-Asp. These data complemented the isotopomer information obtained from the TOCSY analysis described above.

Additional 2-D ${ }^{13} \mathrm{C}$-edited experiments (including HACACO, HCCH-TOCSY, and HSQCTOCSY) were performed for verifying resonance assignment and for discerning the exact ${ }^{13} \mathrm{C}$-labeling pattern in some metabolites, which was ambiguous from the TOCSY and HSQC analysis. For example, it is unclear whether the doublet of $\mathrm{C} 2,5$ of citrate (Fig. 3a, b) represents ${ }^{13} \mathrm{C} 1,{ }^{13} \mathrm{C} 2 /{ }^{13} \mathrm{C} 5,{ }^{13} \mathrm{C} 6,{ }^{13} \mathrm{C} 2,{ }^{13} \mathrm{C} 3 /{ }^{13} \mathrm{C} 3,{ }^{13} \mathrm{C} 5$ or both (cf. Fig. 4 for numbering of citrate). It is also difficult to ascertain whether ${ }^{13} \mathrm{C} 3,{ }^{13} \mathrm{C} 4$-Asp was present based on the TOCSY and HSQC data. This information is crucial to reconstructing the exact pathway(s) from which the labeled isotopomers are derived. For example, using $\left[\mathrm{U}-{ }^{13} \mathrm{C}\right]$-glucose as tracer, ${ }^{13} \mathrm{C} 3,{ }^{13} \mathrm{C} 4$-Asp plus ${ }^{13} \mathrm{C} 1,{ }^{13} \mathrm{C} 2$-Asp are products of the Krebs cycle after one turn while ${ }^{13} \mathrm{C} 1,{ }^{13} \mathrm{C} 2,{ }^{13} \mathrm{C} 3$-Asp is derived from pyruvate carboxylation, an important anaplerotic reaction for the Krebs cycle (Fan et al. 2010).

To address the labeling of the carbonyl groups in the amino acids, we recorded HACACO experiments that correlate the carbonyl carbon with either the $\mathrm{H}_{\mathrm{A}}$, or the side chain carbonyl with $\mathrm{H}_{\mathrm{G}}$; these two carbonyls have significantly different ${ }^{13} \mathrm{C}$ chemical shifts, as shown in Fig. 4. The cross-peaks for $\mathrm{C} 1$ to $\mathrm{H} 2$ (Asp- $\rightarrow 1$ ) and $\mathrm{C} 4$ to $\mathrm{H} 3$ of Asp (Asp-3 $\rightarrow 4$ ) gave credence to the presence of ${ }^{13} \mathrm{C} 1,{ }^{13} \mathrm{C} 2$-Asp and ${ }^{13} \mathrm{C} 3,{ }^{13} \mathrm{C} 4$-Asp. These two products of one turn of the Krebs cycle arise because of the reversible reaction from the symmetric succinate and fumarate to the non-symmetric malate and oxalacetate, an example of metabolic scrambling of label. The cross-peak of $\mathrm{C} 1$ to $\mathrm{H} 2$ of citrate (Cit-2 $\rightarrow 1$ ) indicates the presence of ${ }^{13} \mathrm{C} 1,{ }^{13} \mathrm{C} 2$-citrate, which is also a product of the Krebs cycle after one turn. Further evidence for one turn of Krebs cycle activity came from the cross-peak of $\mathrm{C} 5$ to $\mathrm{H} 4$ of Glu (Glu-4 $\rightarrow 5$ ), which arose from the isotopomer ${ }^{13} \mathrm{C} 4,{ }^{13} \mathrm{C} 5$-Glu. Also detected were the cross-peaks of $\mathrm{C} 1$ to $\mathrm{H} 2$ (Glu-2 $\rightarrow 1$ ) and $\mathrm{C} 1$ to $\mathrm{H} 3$ of Glu (Glu-3 $\rightarrow 1$ ), which corresponded to ${ }^{13} \mathrm{C} 1{ }^{13} \mathrm{C} 2$-Glu and ${ }^{13} \mathrm{C} 1,{ }^{13} \mathrm{C} 2,{ }^{13} \mathrm{C} 3$-Glu, respectively. These two isotopomers could be produced from the Krebs cycle after two and three turns (Fan et al. 2010). It should be noted that the intensity of the Glu- $4 \rightarrow 5$ cross-peak was higher than those of Glu- $2 \rightarrow 1$ and Glu-3 $\rightarrow 1$, which suggests that more cells have undergone only one turn of the Krebs cycle.

${ }^{1} \mathrm{H}\left\{{ }^{13} \mathrm{C}\right\}$ HSQC-TOCSY and ${ }^{1} \mathrm{H}-{ }^{1} \mathrm{H}$ HCCH-TOCSY are complementary experiments that can help determine the enrichment positions and the number of contiguous ${ }^{13} \mathrm{C}$ in the chain, as illustrated in Figs. 5 and 6, respectively. The HSQC-TOCSY provides the ${ }^{13} \mathrm{C}$-edited proton TOCSY connectivity, and where there are multiple ${ }^{13} \mathrm{C}$ in the same compound, the specific cross-peak patterns substantiate the ${ }^{1} \mathrm{H}$ and ${ }^{13} \mathrm{C}$ assignments. The spectrum can be recorded in the same amount of time as the HSQC experiment, but more definitively shows the number of ${ }^{13} \mathrm{C}$ sites in each metabolite, as aided by the ${ }^{1} \mathrm{H}$ connectivities. The HSQCTOCSY experiment can also provide clearer correlations for ${ }^{13} \mathrm{C}$ labeled isotopomers than the TOCSY experiment since spectral contributions from unlabeled species are greatly reduced via the ${ }^{13} \mathrm{C}$ selection in the HSQC part of the experiment. For example, the ${ }^{13} \mathrm{C}$ labeling pattern of Pro was not evident in the TOCSY spectrum (Fig. 2b), but was clearly observed in the HSQC-TOCSY spectrum (Fig. 5b), i.e. the presence of ${ }^{13} \mathrm{C}$ at 2, 3, and 4 positions. Likewise, the presence of ${ }^{13} \mathrm{C} 3$-malate and ${ }^{13} \mathrm{C} 1$ to $\mathrm{C} 6$-glucose was clear in the HSQC-TOCSY (Fig. 5b, d) but not in the TOCSY spectrum (Fig. 2b). 
The HCCH-TOCSY experiment also reduces spectral crowding by selecting only those isotopomers that contains at least two contiguous ${ }^{13} \mathrm{C}$ in the same molecule. This experiment confirmed that the ribose moieties of the free nucleotide pool were predominantly the ${ }^{13} \mathrm{C}_{5}$ isotopomers (Fig. 6c), which indicates their production from the oxidative branch of the pentose phosphate pathway (PPP). However, if the non-oxidative branch of the PPP were significant with the use of non ${ }^{13} \mathrm{C}$ sources, different labeling patterns in the ribose moieties would have been observed. Therefore the NMR data provided a simple means to discriminate between the two branches of the PPP compared with the GC-MS based approaches (Lee et al. 1998). In addition, the connectivity from $\mathrm{H} 1$ to $\mathrm{H} 3$ of the lowabundance glycerol-3-phosphate (GlyOH3P in Fig. 6c) was discernable, which indicates the presence of ${ }^{13} \mathrm{C}_{3}$-GlyOH3P, a precursor to glycerolipid synthesis. Moreover, the connectivity from $\mathrm{H} 2$ to $\mathrm{H} 4$ of the glutamyl moiety of the glutathiones (GSH + GSSG) was observed, which corresponds to the isotopomer ${ }^{13} \mathrm{C} 2,{ }^{13} \mathrm{C} 3,{ }^{13} \mathrm{C} 4-\mathrm{Glu}$. This isotopomer cannot be generated from the Krebs cycle alone even after three turns (Fan et al. 2010). However, ${ }^{13} \mathrm{C}_{5}$-Glu, which contains the ${ }^{13} \mathrm{C} 2,{ }^{13} \mathrm{C} 3,{ }^{13} \mathrm{C} 4$ fragment, can be produced with the input of pyruvate carboxylation (PC) in the first turn of the cycle, according to the scheme in Fig. 7. Finally, the connectivity from $\mathrm{H} 2$ to $\mathrm{H} 3$ of Asp is consistent with the presence of ${ }^{13} \mathrm{C} 1,{ }^{13} \mathrm{C} 2,{ }^{13} \mathrm{C} 3$-Asp, which was also deduced from the HSQC spectrum (Fig. 3a, b).

The isotopomer pattern of Asp generated via mitochondrial Krebs cycle activity should be closely related to that of the uracil ring, which is synthesized from aspartate. The combination of 2-D TOCSY and ${ }^{13} \mathrm{C}$-edited experiments enabled such biosynthetic linkage to be made. Based on HSQC, HACACO, and HCCH-TOCSY data, the ${ }^{13} \mathrm{C}$ isotopomers of Asp detected were ${ }^{13} \mathrm{C} 1,{ }^{13} \mathrm{C} 2$-Asp, ${ }^{13} \mathrm{C} 3,{ }^{13} \mathrm{C} 4$-Asp, and ${ }^{13} \mathrm{C} 1,{ }^{13} \mathrm{C} 2,{ }^{13} \mathrm{C} 3$-Asp. Upon incorporation into the uracil ring, these Asp isotopomers should yield the following ${ }^{13} \mathrm{C}$ isotopomers respectively (see Fig. 4 for uracil ring numbering): ${ }^{12} \mathrm{C} 5,{ }^{13} \mathrm{C} 6-$

uracil, ${ }^{13} \mathrm{C} 5,{ }^{12} \mathrm{C} 6$-uracil, and ${ }^{13} \mathrm{C} 5,{ }^{13} \mathrm{C} 6$-uracil. The TOCSY satellite cross-peak pattern of the uracil ring (cf. Fig. 2d) revealed the presence of all three uracil ${ }^{13} \mathrm{C}$ isotopomers, thereby confirming the biosynthetic route from the tracer $\left[\mathrm{U}-{ }^{13} \mathrm{C}\right]$-glucose through glycolysis, the Krebs cycle with and without PC to pyrimidine ring biosynthesis. This route requires not only an active Krebs cycle in these cells, but also a functioning mitochondrial electron transport chain, as a critical uracil biosynthetic enzyme, dihydroorotate dehydrogenase, is a mitochondrial enzyme (Evans and Guy 2004) (Nagy et al. 1992). This is in contrast to the common notion that mitochondrial functions in cancer cells are compromised (King et al. 2006). It should also be noted that no labeled isotopomers were detected for any of the essential amino acids such as valine, leucine and isoleucine or other essential metabolites such as phosphocholine or nicotinamide, which confirmed the absence of contaminating microbial activity.

${ }^{31} \mathbf{P}$ editing - In addition to ${ }^{13} \mathrm{C}$-edited experiments for determining positional isotopomer profiles in A549 cell extracts, ${ }^{31} \mathrm{P}$-edited 2-D experiments are useful for discerning phosphorylated metabolites without a priori knowledge (Gradwell et al. 1998). There are numerous such metabolites whose concentrations differ substantially among tissue or cell types (Fan and Lane 1992; Gradwell et al. 1998; Vizan et al. 2007). Cancer cells are often characterized by high concentrations of phosphocholine, which has been detected by NMR in vivo (Glunde et al. 2004; Eliyahu et al. 2007). They can also be abundant in nucleotides, which is a critical parameter for tumor cell proliferation. Here, we employed 2-D ${ }^{1} \mathrm{H}\left\{{ }^{31} \mathrm{P}\right\}$ HSQC-TOCSY experiments to determine the identities and relative amounts of phosphorylated compounds in the A549 cell extracts (Fig. 8). Because the phosphomonoesters typically have a $\mathrm{pK}$ near 7 , the ${ }^{31} \mathrm{P}$ chemical shifts are extremely sensitive to solution conditions ( $\mathrm{pH}$, ionic strength, and divalent cations) in cell or tissue lysates. Further complicating the assignment of the ${ }^{31} \mathrm{P}$ signals, the resolution in the ${ }^{31} \mathrm{P}$ dimension for common phosphomonoesters is relatively poor. We therefore used HSQC- 
TOCSY to obtain multiple ${ }^{31} \mathrm{P}-{ }^{1} \mathrm{H}$ correlations in each molecule, thereby making identification of the phosphorylated compounds more reliable. As Fig. 8 shows, the assignment of the highly abundant phosphocholine (P-choline) was substantiated by the connectivity between its two methylene protons and verified by comparison with the standard spectrum (Fan and Lane 2008) (and unpublished data). The same was true for the assignment of 5'ATP, glycerol-3-phosphate, and fructose-6-phosphate (F6P). We estimate that these experiments detect $>50 \mathrm{nmol}$ of phosphorylated compound, which translates roughly to a concentration of $20 \mu \mathrm{M}$ in the cell, in line with reported concentrations of common phosphometabolites in cells (Fersht 1999; Vizan et al. 2007). It should also be noted that glycerol-3-P and F6P could not be unambiguously assigned in ${ }^{1} \mathrm{H}$ and ${ }^{13} \mathrm{C}$-edited experiments due to their low abundance and/or spectral crowding (cf. Fig. 2). However, their presence was clear in the ${ }^{31} \mathrm{P}$-edited experiment (Fig. 8).

${ }^{15} \mathrm{~N}$ editing - Nitrogen metabolism is often dominated by transamination in liver and kidney, which ultimately leads to removal of potentially toxic ammonia via the urea cycle. On the other hand, in several cell types, including cancer cells, glutamine metabolism via glutaminase is up regulated and important for cell proliferation and survival, which makes glutamine a conditionally essentially amino acid. The glutaminase reaction generates ammonium ions and glutamate, which can be used in a wide variety of metabolic reactions, including anaplerotic incorporation of the carbon skeleton into the Krebs cycle (Portais et al. 1996; DeBerardinis et al. 2007; Yuneva 2008). The amido nitrogen of Gln is also the immediate donor for nucleobase biosynthesis and aminosugars such as glucosamine and galactosamine. Thus, ${ }^{15} \mathrm{~N} /{ }^{13} \mathrm{C}-\mathrm{Gln}$ is a useful precursor for tracing numerous metabolic pathways and the resulting products can be detected by ${ }^{1} \mathrm{H}\left\{{ }^{15} \mathrm{~N}\right\}$-HSQC experiments. Figure 9 shows an example spectrum, where the incorporation of the amido $\mathrm{N}$ from ${ }^{13} \mathrm{C}_{5},{ }^{15} \mathrm{~N}_{2}$-Gln into the purine bases in A549 cells was evident. The HSQC experiment utilized the substantial ${ }^{2} \mathrm{~J}_{\mathrm{NH}}$ between $\mathrm{H} 8, \mathrm{~N} 9$ and $\mathrm{H} 2, \mathrm{~N} 1$ for observing $\mathrm{N}-\mathrm{H}$ connectivity in adenine rings of nucleotides (Ippel et al. 1996). As the detected protons do not exchange with solvent, this experiment was carried out in $\mathrm{D}_{2} \mathrm{O}$. In addition, the ${ }^{15} \mathrm{~N}$ satellites of $\mathrm{H} 8$ and $\mathrm{H} 2$ were resolved in the 1-D ${ }^{1} \mathrm{H}$ spectrum, allowing a simple determination of the degree of enrichment following ${ }^{13} \mathrm{C}_{5},{ }^{15} \mathrm{~N}_{2}$-Gln tracer administration to A549 cells (data not shown). Thus, the HSQC analysis enabled the reconstruction of nitrogen pathway from Gln to the synthesis of purine bases. Other ${ }^{15} \mathrm{~N}$ products such as those resulting from transamination can also be detected but only in $\mathrm{H}_{2} \mathrm{O}$, as previously described (Fan et al. 1997).

\section{Analysis of lipid metabolites}

In addition to 2-D NMR analysis of water-soluble metabolites, the same set of experiments can be used to determine isotopomer patterns of lipids, including the membrane phospholipids and cholesterol. Figure 10 shows a TOCSY spectrum of a methanolic extract of A549 cells grown in [U-13 C]-glucose. This solvent extracted primarily polar lipids and cholesterol (Lane et al. 2009). The ${ }^{13} \mathrm{C}$ cross-peak pattern of the glycerol backbone (traced by dashed green boxes) indicates the presence of both all ${ }^{12} \mathrm{C}$ and all ${ }^{13} \mathrm{C}$-labeled isotopomers. There was no evidence for metabolic scrambling of the isotope in the three carbons, which suggests that they were derived from glucose via glycolysis. This is consistent with the observation of the precursor ${ }^{13} \mathrm{C}_{3}-\mathrm{GlyOH} 3 \mathrm{P}$ by HCCH-TOCSY (cf. Fig. 6c). Also evident in Fig. 10a are the ${ }^{13} \mathrm{C}$ cross-peaks of the fatty acyl chains, including those of $\omega \mathrm{CH}_{3}, 2,3,4,8-\mathrm{CH}_{2}$, and unsaturated protons $(\mathrm{CH}=\mathrm{CH})$. Unlike those of the glycerol backbone, these cross-peaks showed scrambled label patterns, i.e. for a given pair of protons, there were four ${ }^{13} \mathrm{C}$ isotopomer species. Using the 2 and $3-\mathrm{CH}_{2}$ correlation as an example, the four isotopomers were ${ }^{12} \mathrm{C} 2{ }^{12} \mathrm{C} 3,{ }^{13} \mathrm{C} 2{ }^{12} \mathrm{C} 3,{ }^{12} \mathrm{C} 2{ }^{13} \mathrm{C} 3$, and ${ }^{13} \mathrm{C} 2{ }^{13} \mathrm{C}$. These patterns are to be expected if the precursor acetyl CoA pool for fatty acid biosynthesis was both unlabeled and uniformly labeled, which in turn means that the citrate precursor to 
acetyl CoA synthesis were both unlabeled and doubly labeled at $\mathrm{C} 1$ and $\mathrm{C} 2$ or $\mathrm{C} 5$ and $\mathrm{C} 6$ positions (cf. Figs. 4 and 7). The ${ }^{13} \mathrm{C} 1,{ }^{13} \mathrm{C} 2$-citrate species was discerned from the HACACO analysis (cf. Fig. 4), while unlabeled citrate was detected by GC-MS (data not shown). It is interesting to note that there were at least three separate sets of unsaturated proton resonances, presumably reflecting different classes of unsaturated lipids.

The ${ }^{13} \mathrm{C}$ labeling pattern of lipids obtained from the TOCSY experiment was complemented and verified by high-resolution HSQC analysis, as shown in Fig. 10. The doublet splitting pattern of $\mathrm{C} \omega$ and $\mathrm{C} 2$ suggests the dominance of acyl chain isotopomers containing the ${ }^{13} \mathrm{CH}_{3}{ }^{13} \mathrm{CH}_{2}{ }^{12} \mathrm{CH}_{2}-$ fragment while the doublet pattern for $\mathrm{C} 3$ and $\mathrm{C} 1$, and triplet pattern for $\mathrm{C} 2$ of the glycerol backbone is consistent with ${ }^{13} \mathrm{C}$ labeling in all three carbons. This information is crucial to interpreting the corresponding FT-ICR-MS data, in terms of assigning the glycerolipid isotopologues of $m+3$ (monoisotopic mass plus 3 neutrons) and $\mathrm{m}+$ odd number of neutrons to ${ }^{13} \mathrm{C}$ labeling in the glycerol backbone (Lane et al. 2009). Together, the NMR and FT-ICR-MS data provide both the number and position of ${ }^{13} \mathrm{C}$ labels in hundreds of lipid species directly in crude cell or tissue extracts, which is a feat unimaginable to achieve in past research.

\section{Conclusions}

The unique spectral editing capabilities of NMR can be used to select and quantify chemical classes such as phosphorylated metabolites, or enriched atoms at specific positions. These capabilities make NMR a technique of choice for reconstruction of metabolic network and quantitative flux analysis, especially when combined with high resolution MS. Both general and specific labeled tracers can be employed to probe different aspects of metabolic networks and how they are perturbed by the environment. We have applied a small fraction of the vast array of possible experiments to determine metabolic labeling topologies, as described here for the A549 cells. Further developments in fast acquisition techniques can increase the sample throughput as well as the information content of stable isotope-resolved metabolomic (SIRM) studies, particularly for the purpose of flux and network modeling in systems biology.

\section{Acknowledgments}

This work was supported in part by National Science Foundation EPSCoR grant \# EPS-0447479; National Institutes of Health Grant numbers 5P20RR018733, 1R01CA118434-01A2, 3R01CA118434-02S1, R21CA133668-01; the Kentucky Challenge for Excellence, and the Brown Foundation. We thank Ms. JinLian Tan for expert technical assistance, and Dr. S. Arumugam for assistance with NMR experiments.

\section{References}

Boren J, Cascante M, Marin S, Comin-Anduix B, Centelles JJ, Lim S, Bassilian S, Ahmed S, Lee WNP, Boros LG. Gleevec (ST1571) influences metabolic enzyme activities and glucose carbon flow toward nucleic acid and fatty acid synthesis in myeloid tumor cells. Journal of Biological Chemistry. 2001; 276(41):37747-37753. [PubMed: 11489902]

Cavanagh, J.; Fairbrother, WJ.; Palmer, AG.; Rance, M.; Skelton, NJ. Protein NMR Spectroscopy: Principles and Practice. Elsevier Academic Press; San Diego: 2007.

Clore GM, Gronenborn AM. Determining the structures of large proteins and protein complexes by NMR. Trends Biotechnol. 1998a; 16(1):22-34. [PubMed: 9470228]

Clore GM, Gronenborn AM. NMR structure determination of proteins and protein complexes larger than $20 \mathrm{kDa}$. Current Opinion in Chemical Biology. 1998b; 2(5):564-570. [PubMed: 9818180]

DeBerardinis RJ, Mancuso A, Daikhin E, Nissim I, Yudkoff M, Wehrli S, Thompson CB. Beyond aerobic glycolysis: Transformed cells can engage in glutamine metabolism that exceeds the 
requirement for protein and nucleotide synthesis. Proc Natl Acad Sci USA. 2007; 104(49):1934519350. [PubMed: 18032601]

Eliyahu G, Kreizman T, Degani H. Phosphocholine as a biomarker of breast cancer: Molecular and biochemical studies. Int J Cancer. 2007; 120(8):1721-1730. [PubMed: 17236204]

Emmerling M, Dauner M, Ponti A, Fiaux J, Hochuli M, Szyperski T, Wuthrich K, Bailey JE, Sauer U. Metabolic flux responses to pyruvate kinase knockout in Escherichia coli. J Bacteriol. 2002; 184(1): 152-164. [PubMed: 11741855]

Ernst, RR.; Bodenhausen, G.; Wokaun, A. Principles of nuclear magnetic resonance in one and two dimensions. Clarendon Press; Oxford: 1990.

Evans DR, Guy HI. Mammalian pyrimidine biosynthesis: Fresh insights into an ancient pathway. Journal of Biological Chemistry. 2004; 279(32):33035-33038. [PubMed: 15096496]

Fan TW-M. Metabolite profiling by one- and two-dimensional NMR analysis of complex mixtures. Prog Nucl Magn Reson Spectrosc. 1996; 28:161-219.

Fan, TW-M. Comprehensive Toxicology. Vol. 2. Academic Press; McQueen, C.A. Oxford: 2010. Metabolomics-Edited Transcriptomics Analysis (Meta).; p. 685-706.

Fan TWM, Lane AN. Identification of Glycerophosphorylcholine in Mussel Ovarian Extracts by 2Dimensional Nuclear-Magnetic-Resonance. Anal Biochem. 1992; 206(2):251-255. [PubMed: 1443594]

Fan TW, Lane AN. Structure-based profiling of Metabolites and Isotopomers by NMR. Progress in NMR Spectroscopy. 2008; 52:69-117.

Fan TWM, Higashi RM, Lane AN, Jardetzky O. Combined use of proton NMR and gas chromatography-mass spectra for metabolite monitoring and in vivo proton NMR assignments. Biochim Biophys Acta. 1986; 882(2):154-167. [PubMed: 3011112]

Fan TWM, Higashi RM, Frenkiel TA, Lane AN. Anaerobic nitrate and ammonium metabolism in flood-tolerant rice coleoptiles. J Exp Bot. 1997; 48(314):1655-1666.

Fan T, Bandura L, Higashi R, Lane A. Metabolomics-edited transcriptomics analysis of Se anticancer action in human lung cancer cells. Metabolomics Journal. 2005; 1(4):325-339.

Fan T, Kucia M, Jankowski K, Higashi R, Ratajczak J, Ratajczak M, Lane A. Rhabdomyosarcoma cells show an energy producing anabolic metabolic phenotype compared with primary myocytes. Molecular Cancer. 2008; 7(1):79. [PubMed: 18939998]

Fan T, Bird J, Brodie E, Lane A. 13C-Isotopomer-based metabolomics of microbial groups isolated from two forest soils. Metabolomics. 2009a; 5(1):108-122.

Fan TW, Lane AN, Higashi RM, Farag MA, Gao H, Bousamra M, Miller DM. Altered regulation of metabolic pathways in human lung cancer discerned by (13)C stable isotope-resolved metabolomics (SIRM). Mol Cancer. 2009b; 8:41. [PubMed: 19558692]

Fan TW-M, Yuan P, Lane AN, Higashi RM, Wang Y, Hamidi A, Zhou R, Guitart X, Chen G, Manji HKM, Kaddurah-Daouk R. Stable Isotope-Resolved Metabolomic Analysis of Lithium Effects on Glial-Neuronal Metabolism and Interactions. Metabolomics. 2010; 6(2):165-179. [PubMed: 20631920]

Fersht, A. Structure and mechanism in protein science. W. H. Freeman \& Co; New York: 1999.

Gardner KH, Kay LE. The use of H-2, C-13, N-15 multidimensional NMR to study the structure and dynamics of proteins. Annu Rev Biophys Biomol Struct. 1998; 27:357-406. [PubMed: 9646872]

Glunde K, Jie C, Bhujwalla ZM. Molecular causes of the aberrant choline phospholipid metabolism in breast cancer. Cancer Res. 2004; 64(12):4270-4276. [PubMed: 15205341]

Gradwell MJ, Fan TWM, Lane AN. Analysis of phosphorylated metabolites in crayfish extracts by two-dimensional 1H-31P NMR heteronuclear total correlation spectroscopy (hetero TOCSY). Anal Biochem. 1998; 263(2):139-149. [PubMed: 9799525]

Ippel J, Wijmenga S, de Jong B, Heus H, Hilbers C, Vroom E, van de Marel C, van Boom JH. Heteronuclear scalar couplings in the bases and sugar rings of nucleic acids: their determination and applicaiotn in assignment and conformational analysis. Magnetic Resoannce in Chemistry. 1996; 34:S156-S176.

Jeng MF, Dyson HJ. Direct measurement of the aspartic acid $26 \mathrm{pK}(\mathrm{a})$ for reduced Escherichia coli thioredoxin by C-13 NMR. Biochemistry. 1996; 35(1):1-6. [PubMed: 8555161] 
King A, Selak MA, Gottlieb E. Succinate dehydrogenase and fumarate hydratase: linking mitochondrial dysfunction and cancer. Oncogene. 2006; 25(34):4675-4682. [PubMed: 16892081]

Lane AN, Fan TW. Quantification and identification of isotopomer distributions of metabolites in crude cell extracts using 1H TOCSY. Metabolomics. 2007; 3:79-86.

Lane AN, Fan TW, Higashi RM. Isotopomer-based metabolomic analysis by NMR and mass spectrometry. Biophysical Tools for Biologists. 2008; 84:541-588.

Lane AN, Fan TW-M, Xie X, Moseley HN, Higashi RM. Stable isotope analysis of lipid biosynthesis by high resolution mass spectrometry and NMR Anal. Chim. Acta. 2009; 651:201-208.

Lee W-NP, Boros LG, Puigjaner J, Bassilian S, Lim S, Cascante M. Mass isotopomer study of the nonoxidative pathways of the pentose cycle with [1, 2-13C2] glucose. Am J Physiol Endocrinol Metab. 1998; 274(5):E843-E851.

Lindon JC, Holmes E, Nicholson JK. Metabonomics: Systems biology in pharmaceutical research and development. Current Opinion in Molecular Therapeutics. 2004; 6(3):265-272. [PubMed: 15264428]

Lu D, Mulder H, Zhao P, Burgess SC, Jensen MV, Kamzolova S, Newgard CB, Sherry AD. 13C NMR isotopomer analysis reveals a connection between pyruvate cycling and glucose-stimulated insulin secretion (GSIS). Proc Natl Acad Sci USA. 2002; 99(5):2708-2713. [PubMed: 11880625]

Lundstrom P, Teilum K, Carstensen T, Bezsonova I, Wiesner S, Hansen DF, Religa TL, Akke M, Kay LE. Fractional C-13 enrichment of isolated carbons using [1-C-13]- or [2-C-13]-glucose facilitates the accurate measurement of dynamics at backbone $\mathrm{C}$-alpha and side-chain methyl positions in proteins. J Biomol NMR. 2007; 38(3):199-212. [PubMed: 17554498]

Maaheimo H, Fiaux J, Cakar ZP, Bailey JE, Sauer U, Szyperski T. Central carbon metabolism of Saccharomyces cerevisiae explored by biosynthetic fractional C-13 labeling of common amino acids. Eur J Biochem. 2001; 268(8):2464-2479. [PubMed: 11298766]

Nagy M, Lacroute F, Thomas D. Divergent evolution of pyrimidine biosynthesis between anaerobic and aerobic yeasts. Proc Natl Acad Sci U S A. 1992; 89(19):8966-8970. [PubMed: 1409592]

Portais JC, Voisin P, Merle M, Canioni P. Glucose and glutamine metabolism in C6 glioma cells studied by carbon 13 NMR. Biochimie. 1996; 78(3):155-164. [PubMed: 8831946]

Qin J, Clore GM, Gronenborn AM. Ionization equilibria for side-chain carboxyl groups in oxidized and reduced human thioredoxin and in the complex with its target peptide from the transcription factor NF kappa B. Biochemistry. 1996; 35(1):7-13. [PubMed: 8555200]

Rittenberg D, Schoenheimer R. Deuterium as an indicator in study of intermediatory metabolism. VIII. Hydrogenation of fatty acids in the animals organism. J. Biol. Chem. 1937; 117:485-490.

Sherry AD, Jeffrey FMH, Malloy CR. Analytical solutions for C-13 isotopomer analysis of complex metabolic conditions: substrate oxidation, multiple pyruvate cycles, and gluconeogenesis. Metabolic Engineering. 2004; 6(1):12-24. [PubMed: 14734252]

Trygg J, Holmes E, Lundstedt T. Chemometrics in metabonomics. J Proteome Res. 2007; 6(2):469479. [PubMed: 17269704]

Vizan P, Alcarraz-Vizan G, Diaz-Moralli S, Rodriguez-Prados JC, Zanuy M, Centelles JJ, Jauregui O, Cascante M. Quantification of intracellular phosphorylated carbohydrates in HT29 human colon adenocarcinoma cell line using liquid chromatography-electrospray ionization tandem mass spectrometry. Anal Chem. 2007; 79(13):5000-5005. [PubMed: 17523595]

Yuneva M. Finding an "Achilles' heel” of cancer: the role of glucose and glutamine metabolism in the survival of transformed cells. Cell Cycle. 2008; 7:2083-2089. [PubMed: 18635953] 


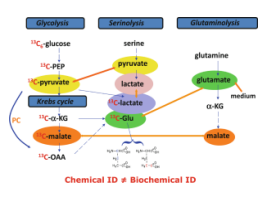

Fig. 1.

Tracers are necessary for delineating metabolic pathways. In the scheme depicted, pyruvate, lactate, $\alpha$-ketoglutarate $(\alpha-\mathrm{KG})$, malate and Glu participate in multiple pathways including glycolysis, the Krebs cycle, serinolysis, and glutaminolysis. Without labeled tracers, it is impractical to resolve the specific pathway(s) involved in their production. With the use of ${ }^{13} \mathrm{C}_{6}$-glucose, the synthesis of pyruvate, lactate, $\alpha-\mathrm{KG}$, malate, and Glu via glycolysis and the Krebs cycle can be distinguished from that via serinolysis or glutaminolysis by the ${ }^{13} \mathrm{C}$ labeling pattern of these metabolites. Furthermore, the ${ }^{13} \mathrm{C}$ positional isotopomers of Glu (i.e. ${ }^{13} \mathrm{C}-2,3-$ Glu and ${ }^{13} \mathrm{C}-4,5-\mathrm{Glu}$ ) can be used to delineate respectively the Krebs cycle with or without pyruvate carboxylation (PC) input. In essence, chemical identity of metabolites does not equate to their biochemical origin, which requires labeled isotopomers for their resolution 

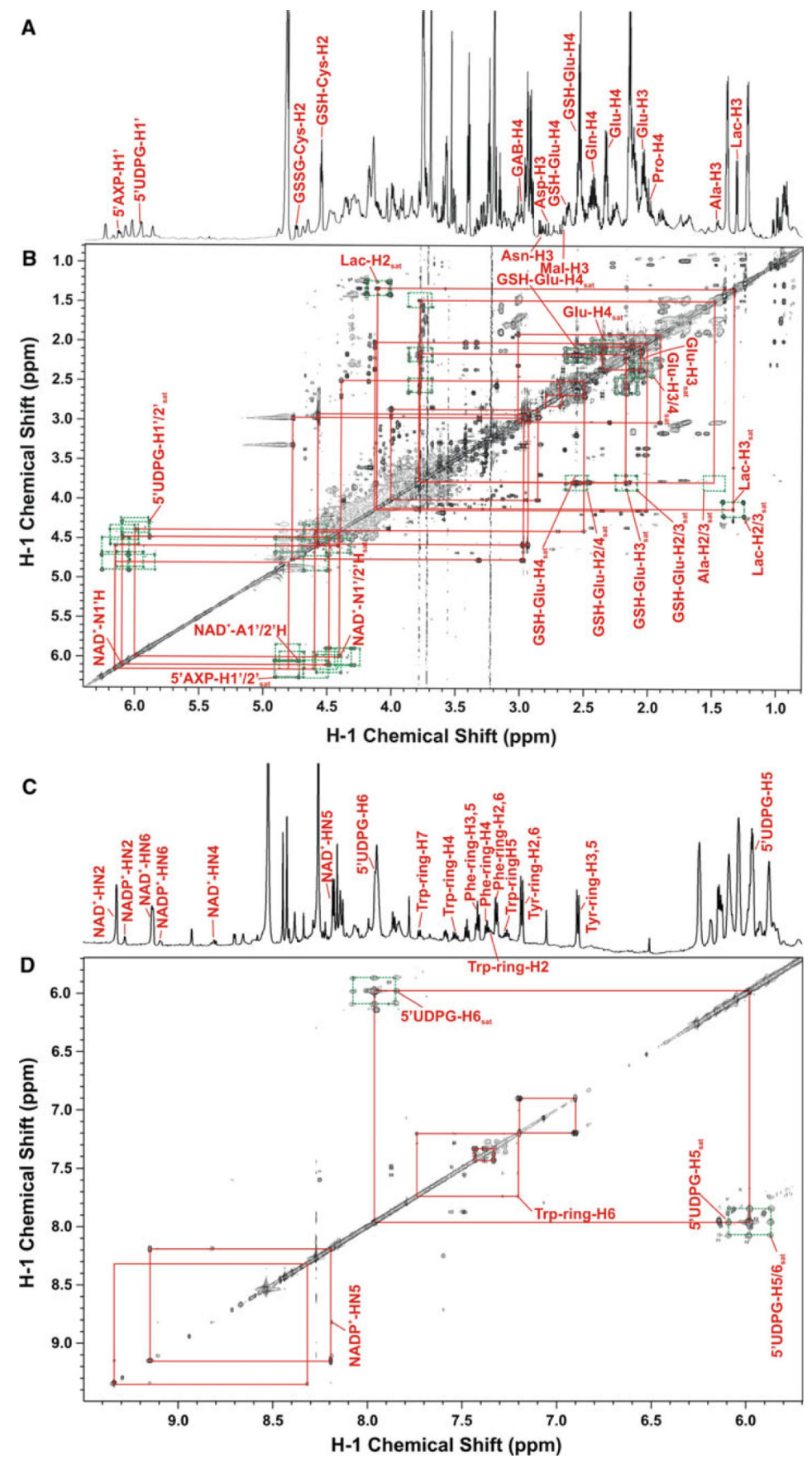

Fig. 2.

Positional ${ }^{13} \mathrm{C}$ enrichment detected from satellite patterns in ${ }^{1} \mathrm{H}-{ }^{1} \mathrm{H}$ TOCSY spectrum of an A549 cell extract. The cells were grown in the presence of $10.75 \mathrm{mM}\left[\mathrm{U}-{ }^{13} \mathrm{C}\right]$-glucose for $24 \mathrm{~h}$, and the metabolites were extracted as described in the "Methods". NMR spectra were recorded at $800 \mathrm{MHz}$ and $20^{\circ} \mathrm{C}$. A,C 1-D ${ }^{1} \mathrm{H}$ spectrum recorded with an acquisition time of $2 \mathrm{~s}$, a relaxation delay of $3 \mathrm{~s}$, and pre-saturation of the HOD signal. Data were processed by zerofilling once and apodizing with an unshifted Gaussian function and a $1 \mathrm{~Hz}$ line broadening exponential. B,D The TOCSY spectrum was recorded with acquisition times of $0.512 \mathrm{~s}$ in $t_{2}$ and $0.038 \mathrm{~s}$ in $t_{1}$, linear-predicted in F1, zero-filled to $8 \mathrm{k}$ by $2 \mathrm{k}$ points, and apodized with an unshifted Gaussian function and a $1 \mathrm{~Hz}$ line broadening exponential in 
both dimensions. Total experiment time was $11.2 \mathrm{~h}$. Assignments were based on standards recorded under identical conditions (Fan and Lane 2008). Red rectangles trace the ${ }^{1} \mathrm{H}-{ }^{1} \mathrm{H}$ connectivities while dashed green boxes depict the ${ }^{13} \mathrm{C}$ satellite cross-peak patterns (e.g. Lac-H3 $\left.3_{\text {sat }}\right)$. Lac lactate, Mal malate, GSH reduced glutathione, GSSG oxidized glutathione, $G A B \gamma$-aminobutyrate. Metabolite numbering was according to (Fan and Lane 2008) 


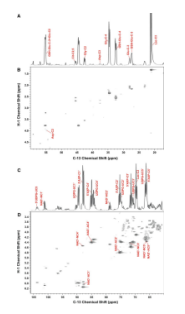

Fig. 3.

High resolution ${ }^{1} \mathrm{H}\left\{{ }^{13} \mathrm{C}\right\}$-HSQC shows ${ }^{13} \mathrm{C}-{ }^{13} \mathrm{C}$ couplings in labeled metabolites of A549 extract. The sample was the same as in Fig. 2. The HSQC spectrum was recorded with acquisition times of $0.15 \mathrm{~s}$ in $t_{2}$ and $0.025 \mathrm{~s}$ in $t_{1}$ with a recycle time of $1.5 \mathrm{~s}$. GARP decoupling was applied during $t_{2}$. The data were zerofilled once in $t_{2}$, linear predicted and zerofilled in $t_{1}$ to a final digital resolution of $5.9 \mathrm{~Hz} / \mathrm{pt}$. The data were apodized using an unshifted Gaussian and a line broadening exponential of $1 \mathrm{~Hz}$ in $\mathrm{F} 2$ and $4 \mathrm{~Hz}$ in $\mathrm{F} 1$. Total experiment time was $32 \mathrm{~h}$. a, c are projections on the ${ }^{13} \mathrm{C}$ axis. $\mathbf{b}$ aliphatic region, $\mathbf{d}$ sugar and pyrimidine $\mathrm{C} 5$ region. Cit citrate, all other abbreviations and numbering are as in Fig. 2. The ${ }^{13} \mathrm{C}$ chemical shift was referenced indirectly to ${ }^{1} \mathrm{H}$, which was $0.5 \mathrm{ppm}$ higher than those referenced directly to DSS (Fan 1996) 


\section{Citric acid}
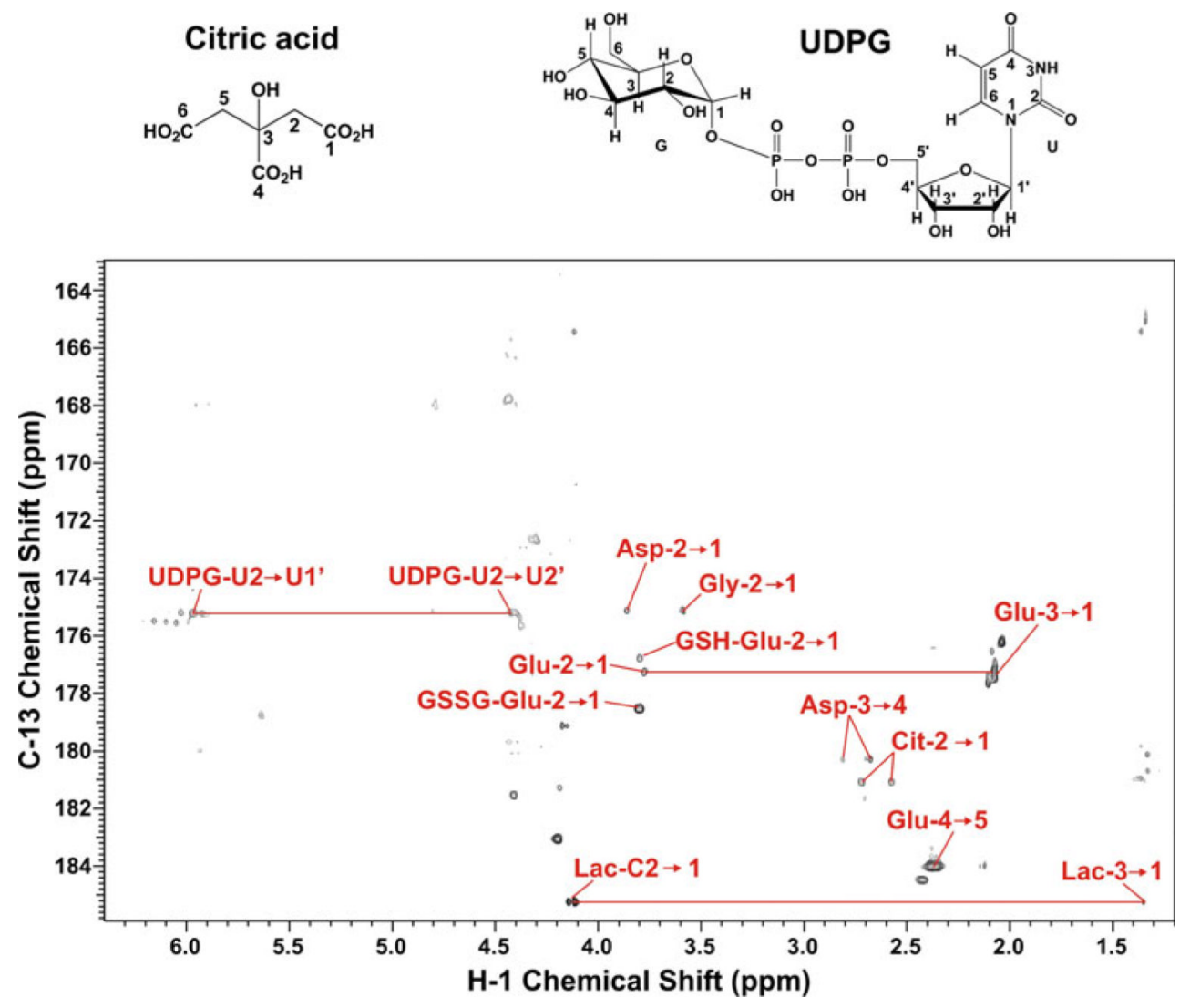

Fig. 4.

HACACO experiments directly detect ${ }^{13} \mathrm{C}$-labeled carbonyls. The sample was similarly prepared as in Fig. 2. The spectrum was recorded to detect the CO-HA,HB,HG plane with a ${ }^{13} \mathrm{C}$ offset set to $55 \mathrm{ppm}$. The acquisition times were $0.12 \mathrm{~s}$ in $t_{2}$, and $0.042 \mathrm{~s}$ in $t_{1}$ with a recycle time of $1.3 \mathrm{~s}$. The data were zerofilled once in $t_{2}$, and linear predicted and zerofilled in $t_{1}$. The data were apodized using an unshifted Gaussian and a line broadening exponential of $1 \mathrm{~Hz}$ in $\mathrm{F} 2$ and $4 \mathrm{~Hz}$ in F1. Total experiment time was $5.9 \mathrm{~h}$. The chemical shift displayed was $2.1 \mathrm{ppm}$ higher than that referenced to DSS for Gly. The abbreviations and numbering were the same as in Fig. 2. Also shown are the structures and numbering of citric acid and UDPG 
A
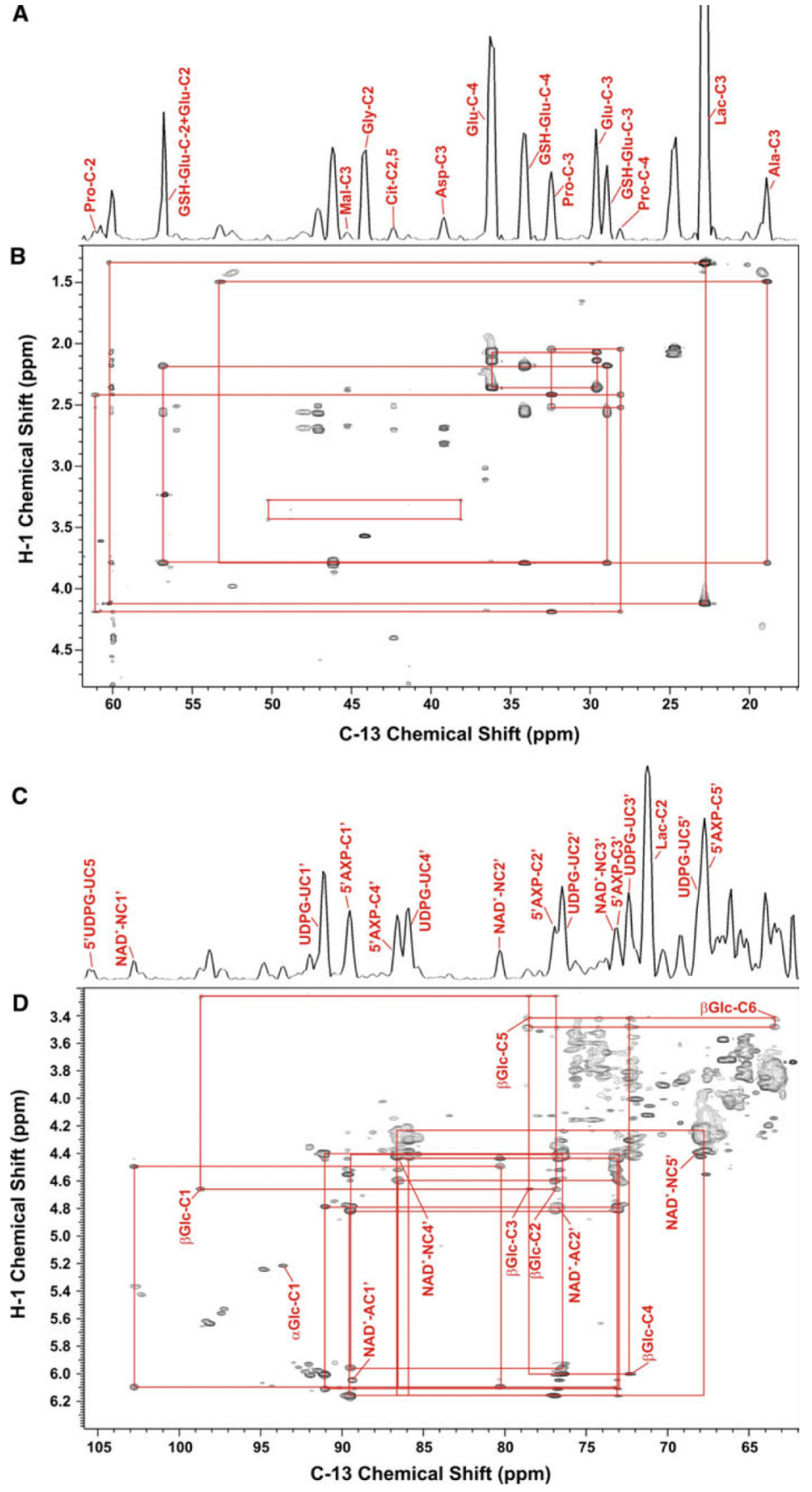

Fig. 5.

${ }^{1} \mathrm{H}\left\{{ }^{13} \mathrm{C}\right\}$ HSQC-TOCSY verifies ${ }^{13} \mathrm{C}$ isotopomer assignment and reduces spectral crowding. The sample was the same as in Fig. 4. The HSQC-TOCSY spectrum was recorded with GARP decoupling during $t_{2}(0.14 \mathrm{~s})$ centered at $60 \mathrm{ppm}$ in the ${ }^{13} \mathrm{C}$ dimension, and a recycle time of $1.5 \mathrm{~s}$. The acquisition time in $t_{1}$ was $0.0125 \mathrm{~s}$. The spin lock strength was $8 \mathrm{kHz}$ for $50 \mathrm{~ms}$. The data were zerofilled in $t_{2}$, and linear predicted and zerofilled in $t_{1}$ to $8 \mathrm{k} \times 2 \mathrm{k}$ points. The data were apodized using an unshifted Gaussian and a line broadening exponential of $1 \mathrm{~Hz}$ in $\mathrm{F} 2$ and $4 \mathrm{~Hz}$ in F1. Total experiment time was $6 \mathrm{~h}$. a, b aliphatic region. $\mathbf{a}$ is the ${ }^{13} \mathrm{C}$ projection of $\mathbf{b} . \mathbf{c}, \mathbf{d}$ sugar and pyrimidine $\mathrm{C} 5$ region. $\mathbf{c}$ is the ${ }^{13} \mathrm{C}$ projection of $\mathbf{b}$. The abbreviations and numbering were the same as in Fig. 2 


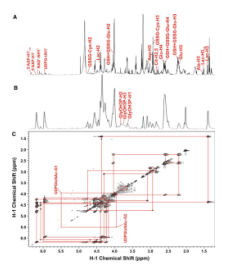

Fig. 6.

${ }^{1} \mathrm{H}-{ }^{1} \mathrm{H}$ HCCH-TOCSY reveals numbers of contiguous ${ }^{13} \mathrm{C}$ atoms in isotopomers. The sample was similarly prepared as in Fig. 2 except that the cells were extracted in $10 \%$ trichloroacetic acid. The HCCH-TOCSY spectrum was recorded at $14.1 \mathrm{~T}$ with GARP decoupling during $t_{2}(0.12 \mathrm{~s})$ centered at $60 \mathrm{ppm}$ in the ${ }^{13} \mathrm{C}$ dimension, and a recycle time of $1.5 \mathrm{~s}$. The acquisition tine in $t_{1}$ was $0.05 \mathrm{~s}$. The spin lock strength was $8 \mathrm{kHz}$ for $11 \mathrm{~ms}$. The data were zerofilled in $t_{2}$, and linear predicted and zerofilled in $t_{1}$ to $8 \mathrm{k} \times 2 \mathrm{k}$ points. The data were apodized using an unshifted Gaussian and a line broadening exponential of $1 \mathrm{~Hz}$ in $\mathrm{F} 2$ and $4 \mathrm{~Hz}$ in $\mathrm{F} 1$. Total experiment time was $11.4 \mathrm{~h}$. a high resolution 1-D ${ }^{1} \mathrm{H}$ spectrum. b Projection of the $2 \mathrm{D}$ spectrum onto the $\mathrm{F} 2$ axis showing spectral simplification via ${ }^{13} \mathrm{C}$ editing. c 2-D spectrum of the same region in a, b. GlyOH3P glycerol-3-phosphate, all other abbreviations and numbering were the same as in Fig. 2 


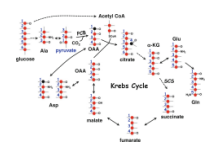

Fig. 7.

Labeling scheme for the Krebs cycle with pyruvate carboxylation using [U- $\left.{ }^{13} \mathrm{C}\right]$-glucose as tracer. Red circles are ${ }^{13} \mathrm{C}$ atoms, black circles are ${ }^{12} \mathrm{C}$ atoms. Double and single headed arrows represent reversible and irreversible reactions, respectively; dashed arrows depict multiple reaction steps. $O A A$ oxalacetate, $S C S$ succinyl CoA synthetase, $P C B$ pyruvate carboxylase 


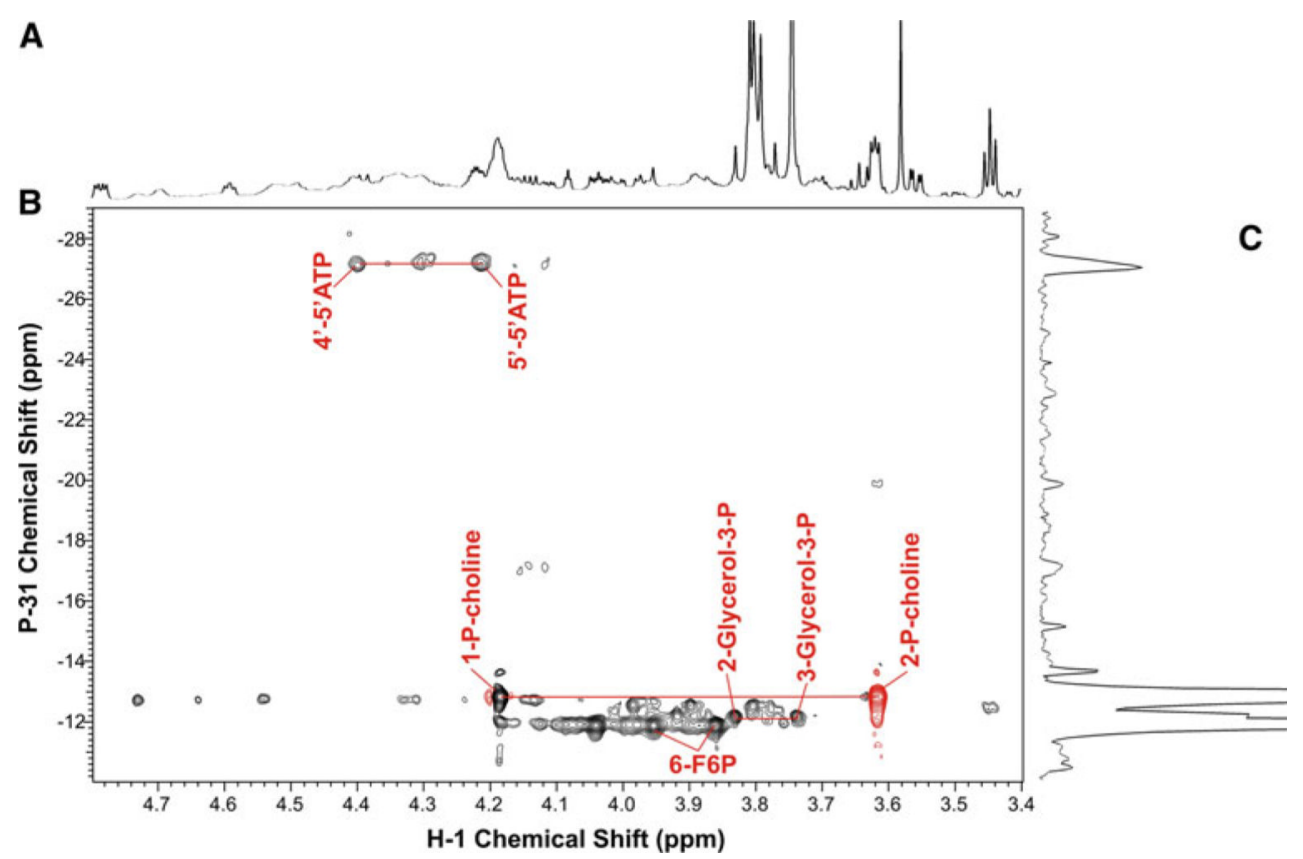

Fig. 8.

Spectral editing via ${ }^{1} \mathrm{H}\left\{{ }^{31} \mathrm{P}\right\}$ HSQC-TOCSY for the assignment of phosphorylated metabolites. The sample was the same as in Fig. 4 . The ${ }^{1} \mathrm{H}-\left\{{ }^{31} \mathrm{P}\right\}$ HSQC-TOCSY spectrum was recorded with acquisition time of $0.14 \mathrm{~s}$ in $t_{2}$ and $0.014 \mathrm{~s}$ in $t_{1}$, with a recycle time of $1.35 \mathrm{~s}$ and GARP decoupling during $t_{2}$ The spin lock strength was $8 \mathrm{kHz}$ for $50 \mathrm{~ms}$. Total experiment time was $13.9 \mathrm{~h}$. The ${ }^{31} \mathrm{P}$ spectrum was referenced to external methylene diphosphonate (Gradwell et al. 1998). a 1-D high resolution ${ }^{1} \mathrm{H}$ spectrum. b 2-D spectrum. c 1-D projection on the ${ }^{31} \mathrm{P}$ axis 


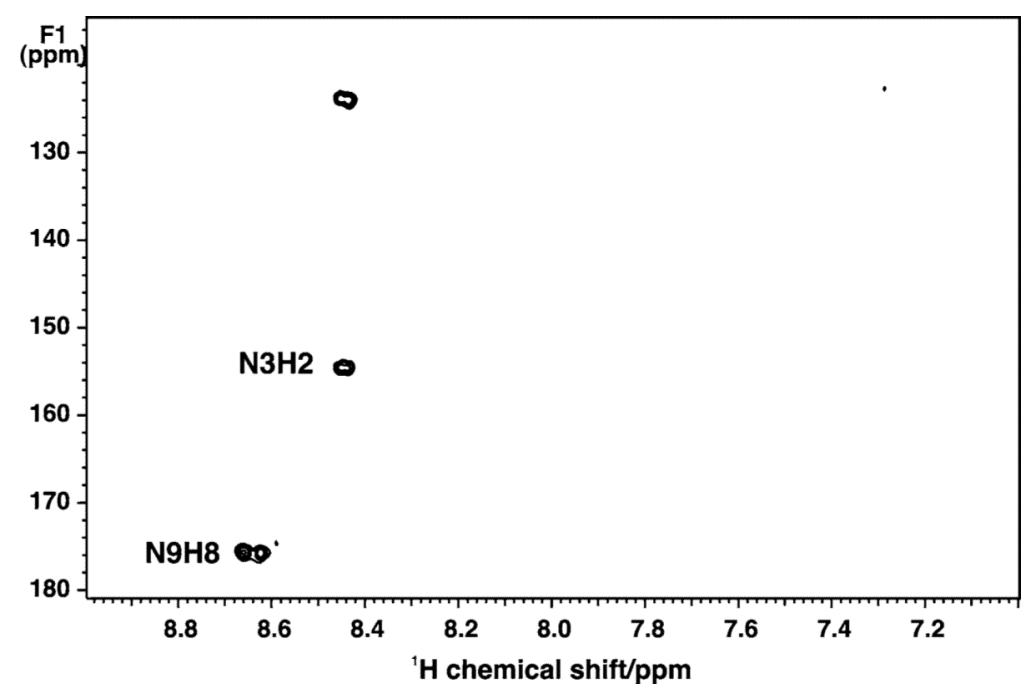

Fig. 9.

Spectral editing via ${ }^{1} \mathrm{H}\left\{{ }^{15} \mathrm{~N}\right\}$-HSQC detects ${ }^{15} \mathrm{~N}$-isotopomers of nucleotides. A549 cells were grown for $24 \mathrm{~h}$ in the presence of $5 \mathrm{mM}$ unlabeled glucose and $4 \mathrm{mM}\left[\mathrm{U}-{ }^{13} \mathrm{C},{ }^{15} \mathrm{~N}\right]-$ glutamine and extracted as described in the "Methods". The spectrum was recorded at 14.1 $\mathrm{T}$ at $20^{\circ} \mathrm{C}$ with acquisition times of $0.15 \mathrm{~s}$ in $t_{2}$ and $0.021 \mathrm{~s}$ in $t_{1}$ and a recycle time of $1.6 \mathrm{~s}$. The value of $\mathrm{J}_{\mathrm{NH}}$ was set to $10 \mathrm{~ms}$. The data were zerofilled in $t_{2}$, linear predicted and zerofilled in $t_{1}$ to a final $8 \mathrm{k}$ by $2 \mathrm{k}$ points, apodized with an unshifted Gaussian and a $1 \mathrm{~Hz}$ line broadening exponential in both dimensions. Total experiment time was $0.91 \mathrm{~h}$ 

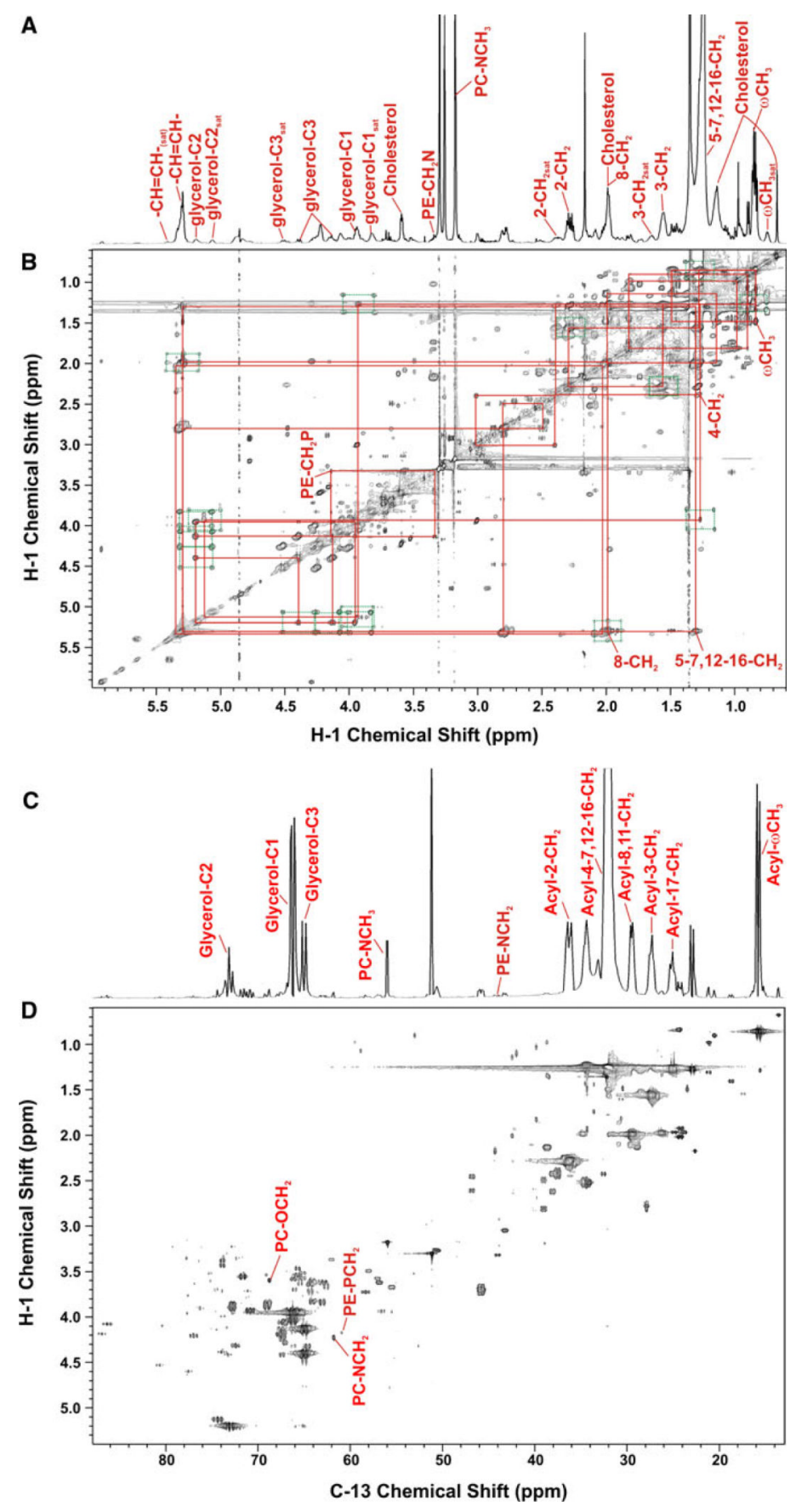

Fig. 10.

${ }^{13} \mathrm{C}$ enrichment in PL isotopomers determined by ${ }^{1} \mathrm{H}-{ }^{1} \mathrm{H}$ TOCSY and highresolution ${ }^{1} \mathrm{H}\left\{{ }^{13} \mathrm{C}\right\}$ - HSQC. The A549 cells were grown in [U-13 $\left.\mathrm{C}\right]$-glucose for $24 \mathrm{~h}$ before extraction with pure methanol as described in the "Methods". The TOCSY spectrum was recorded at $14.1 \mathrm{~T}$ with acquisition times of $0.341 \mathrm{~s}$ in $t_{2}$ and $0.043 \mathrm{~s}$ in $t_{1}$ respectively and a recycle time of $2 \mathrm{~s}$. The total experiment time was $10.9 \mathrm{~h}$. The high resolution HSQC spectrum was recorded with acquisition times of $0.12 \mathrm{~s}$ and $0.034 \mathrm{~s}$ in $t_{1}$ and $t_{2}$, respectively with a recycle time of $2.1 \mathrm{~s}$. Total experiment time was $16.7 \mathrm{~h}$. Processing was as described in Figs. 2 and 9. a, b 1-D proton spectrum and TOCSY of the aliphatic region of the spectrum. Assignments were based on lipid standards recorded under the same conditions 
(Lane et al. 2009). c, $\mathbf{d}$ high resolution HSQC spectrum (d) and the 1-D ${ }^{13} \mathrm{C}$ projection (c). Metabolite nomenclature and numbering are as described in (Fan and Lane 2008) 
Table 1

2-D ${ }^{1} \mathrm{H}$ TOCSY quantification of different ${ }^{13} \mathrm{C}$ positional isotopomers of glycolytic and Krebs cycle metabolites in an example A549 cell extract

\begin{tabular}{|c|c|}
\hline Isotopomers $^{a}$ & Fraction \\
\hline${ }^{12} \mathrm{C}-2,{ }^{12} \mathrm{C}$ 4-Glu-GSH & 0.725 \\
\hline${ }^{13} \mathrm{C}-2,{ }^{12} \mathrm{C}-4-\mathrm{Glu}-\mathrm{GSH}$ & 0.024 \\
\hline${ }^{13} \mathrm{C}-4,{ }^{12} \mathrm{C}-2$-Glu-GSH & 0.150 \\
\hline${ }^{13} \mathrm{C}-2,{ }^{13} \mathrm{C}-4-G l u-G S H$ & 0.102 \\
\hline${ }^{12} \mathrm{C}-2,{ }^{12} \mathrm{C}-3$-Glu-GSH & 0.839 \\
\hline${ }^{13} \mathrm{C}-2,{ }^{12} \mathrm{C}-3$-Glu-GSH & 0.067 \\
\hline${ }^{13} \mathrm{C}-3,{ }^{12} \mathrm{C}-2$-Glu-GSH & 0.026 \\
\hline${ }^{13} \mathrm{C}-2,{ }^{13} \mathrm{C}-3-\mathrm{Glu}-\mathrm{GSH}$ & 0.069 \\
\hline${ }^{12} \mathrm{C}-3,{ }^{12} \mathrm{C}-4-\mathrm{Glu}-\mathrm{GSH}$ & 0.647 \\
\hline${ }^{13} \mathrm{C}-3,{ }^{12} \mathrm{C}-4-\mathrm{Glu}-\mathrm{GSH}$ & 0.008 \\
\hline${ }^{13} \mathrm{C}-4,{ }^{12} \mathrm{C}-3$-Glu-GSH & 0.296 \\
\hline${ }^{13} \mathrm{C}-3,{ }^{13} \mathrm{C}-4-\mathrm{Glu}-\mathrm{GSH}$ & 0.049 \\
\hline${ }^{12} \mathrm{C}-3,{ }^{12} \mathrm{C}-4-\mathrm{Glu}$ & 0.619 \\
\hline${ }^{13} \mathrm{C}-4,{ }^{12} \mathrm{C}-3-\mathrm{Glu}$ & 0.381 \\
\hline${ }^{12} \mathrm{C}-2,{ }^{12} \mathrm{C}-3$-Lactate & 0.042 \\
\hline${ }^{13} \mathrm{C}-2,{ }^{12} \mathrm{C}-3$-Lactate & 0.016 \\
\hline${ }^{13} \mathrm{C}-3,{ }^{12} \mathrm{C}-2$-Lactate & 0.005 \\
\hline${ }^{13} \mathrm{C}-2,{ }^{13} \mathrm{C}-3$-Lactate & 0.937 \\
\hline${ }^{12} \mathrm{C}-2,{ }^{12} \mathrm{C}-3-\mathrm{Ala}$ & 0.137 \\
\hline${ }^{13} \mathrm{C}-2,{ }^{13} \mathrm{C}-3$-Ala & 0.863 \\
\hline${ }^{12} \mathrm{C}-1^{\prime},{ }^{12} \mathrm{C}-2^{\prime}-5^{\prime} \mathrm{AXP}$ & 0.117 \\
\hline${ }^{13} \mathrm{C}-1^{\prime},{ }^{13} \mathrm{C}-2^{\prime}-\mathrm{AXP}$ & 0.883 \\
\hline${ }^{12} \mathrm{C}-1^{\prime},{ }^{12} \mathrm{C}-2^{\prime}-5^{\prime} \mathrm{CXP}$ & 0.222 \\
\hline${ }^{13} \mathrm{C}-1^{\prime},{ }^{13} \mathrm{C}-2^{\prime}-5^{\prime} \mathrm{CXP}$ & 0.778 \\
\hline${ }^{12} \mathrm{C}-1^{\prime},{ }^{12} \mathrm{C}-2^{\prime}$-UDPG & 0.073 \\
\hline${ }^{13} \mathrm{C}-1^{\prime},{ }^{13} \mathrm{C}-2^{\prime}$-UDPG & 0.927 \\
\hline${ }^{12} \mathrm{C}-\mathrm{U} 5,{ }^{12} \mathrm{C}-6-\mathrm{UDPG}$ & 0.614 \\
\hline${ }^{13} \mathrm{C}-\mathrm{U} 5,{ }^{12} \mathrm{C}-\mathrm{U} 6-\mathrm{UDPG}$ & 0.106 \\
\hline${ }^{13} \mathrm{C}-\mathrm{U} 6,{ }^{12} \mathrm{C}-\mathrm{U} 5-\mathrm{UDPG}$ & 0.135 \\
\hline${ }^{13} \mathrm{C}$-U5, ${ }^{13} \mathrm{C}$-6-UDPG & 0.145 \\
\hline${ }^{12} \mathrm{C}-\mathrm{A} 1^{\prime},{ }^{12} \mathrm{C}-\mathrm{A} 2^{\prime}-\mathrm{NAD}^{+}$ & 0.214 \\
\hline${ }^{13} \mathrm{C}-\mathrm{A} 1^{\prime},{ }^{13} \mathrm{C}-\mathrm{A} 2^{\prime}-\mathrm{NAD}^{+}$ & 0.786 \\
\hline
\end{tabular}

$G S H$ reduced glutathione, $A X P$ adenine nucleotides, $C X P$ cytosine nucleotides, $U D P G$ uracildiphospho glucose, $N A D^{+}$nicotinamide adenine dinucleotide

$a_{\text {Isotopomer assignment and numbering are as described in (Fan et al. 2008) }}$ 